City University of New York (CUNY)

CUNY Academic Works

\title{
Microanalytical Investigations of Gold-Bearing Rocks from the An Najadi Region in Saudi Arabia
}

\author{
Nazrul I. Khandaker \\ cUNY York College
}

M. Ahmed

King Fahd University of Petroleum and Minerals

M. M. Hariri

King Fahd University of Petroleum and Minerals

M. A. Garwan

King Fahd University of Petroleum and Minerals

K. R. Khan

King Fahd University of Petroleum and Minerals

See next page for additional authors

\section{How does access to this work benefit you? Let us know!}

More information about this work at: https://academicworks.cuny.edu/yc_pubs/82

Discover additional works at: https://academicworks.cuny.edu

This work is made publicly available by the City University of New York (CUNY).

Contact: AcademicWorks@cuny.edu 


\section{Authors}

Nazrul I. Khandaker, M. Ahmed, M. M. Hariri, M. A. Garwan, K. R. Khan, and M. M. Al-Ohali 


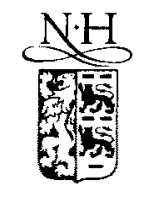

\title{
Microanalytical investigations of gold-bearing rocks from the An Najadi region in Saudi Arabia
}

\author{
N.I. Khandaker ${ }^{a, *}$, M. Ahmed ${ }^{b}$, M.M. Hariri ${ }^{a}$, M.M. Al-Ohali ${ }^{\text {b,c }}$, M.A. Garwan ${ }^{\text {b.c }}$, \\ K.R. Khan ${ }^{\text {a }}$ \\ "Earth Sciences Department, King Fahd University of Petroletum \& Minerals, Box 1172. Dhahran 31261, Saudi Arabia \\ ${ }^{\circ}$ Energy Resources Diuision, Research Institute. King Fahd Unicersity of Petroleum \& Minerals, Dhahran 3/261, Saudi Arabia \\ 'Physics Department. King Fahd University of Petroleum \& Minerals, Dhahran 31261. Saudi Arabia
}

\begin{abstract}
The Proton Induced X-ray Emission technique with a scanning microbeam (micro-PIXE) and Scanning Electron Microscopy (SEM) were employed to study gold-bearing rocks from the An Najadi and adjacent regions situated within the exposed northeastern part of the Arabian Shield. These microanalytical investigations, together with routine petrological and ore microscopic studies, demonstrated the presence of important partitioning of major minerals and trace elements in several samples. These measurements also revealed microstructural features including brecciation within quartz grains and metal concentrations within these fracture-controlled micro-conduits. Results showed promise in terms of using distinctive geochemical signatures for ore body recognition. Of particular interest to this study is the presence of an identifiable geochemical trend pertaining to $\mathrm{As}, \mathrm{Ti}, \mathrm{Zn}, \mathrm{Cu}, \mathrm{Fe}$ and $\mathrm{Au}$. Overall geochemical and petrological data indicate an epithermal mineralization phenomenon for the metal deposits in the An Najadi regions. Mineralization not only postdated brecciation but also followed the regional structural grain of this area. (C) 1997 Elsevier Science B.V.
\end{abstract}

\section{Introduction}

The An Najadi area $\left(26^{\circ}\right.$ North; $42^{\circ}$ East) is situated within the exposed northeastern part of the Arabian Shield and constitutes a critical locality in terms of hosting several important gold mineralization units in the Kingdom of Saudi Arabia [1]. The An-Najadi mineral belt is underlain by Proterozoic clastic and metasedimentary rocks of the Murdama group [2]. Gold is hosted by the Proterozoic diorite intrusive emplaced around 610-630 $\mathrm{Ma}$ ago [3].

\footnotetext{
"Corresponding author. Fax: +966 38602595 ; e-mail: nislam@dpe.kfupm.edu.sa.
}

There are signs of numerous ancient mining sites and these are situated along veins cutting quartz diorite intrusives. These ancient mining sites are often utilized by various exploration companies for undertaking additional reconnaissance work related to metal exploration. Two distinctive zones are recognized in the An Najadi regions: an altered upper horizon and an unaltered lower horizon $[4,5]$. The altered horizon is several meters thick and often contains chlorite. Gold is economically exploited both from altered and unaltered zones [6].

Currently several open-pit mines are in operation to recover gold from this locality. However, detailed geological and geochemical studies of these goldbearing localities are very limited. Several key ques- 
tions related to the ore mineralization warrant detailed investigations before any conclusion can be drawn regarding gold genesis, geochemical environment, and tectonic setting:

- Are there any direct chemical signatures associated with the mineralization ore body?

- What was the paleotectonic setting of this region?

- And finally, is there any site-specific geological model that can explain gold genesis in these areas?

The present study was initiated to answer some of the above questions by petrological and microanalyses of samples from the An Najadi and adjacent areas. Specific objectives of these measurements were:

1. Determine chemical and lithological constraints on gold mineralization.

2. Determine the bulk and trace element partitioning within individual mineralization zones.

3. Utilize chemical data to devise a discriminant function for fingerprinting individual mineralization zones.

4. Relate geological and geochemical data to reconstruct paleotectonic setting and its resultant gold mineralization process.

5. Provide geologists working on Precambrian gold deposits and gold explorationists with an effective scenario for gold mineralization process.

\section{Method}

\subsection{Sample preparation}

Representative samples were collected from the An Najadi and adjacent regions during 1995 and 1996. Special attention was focused on ore-bearing quartz vein, quartz diorite, and both altered and unaltered zones. Polished thin sections (about 30 microns thick), polished rock slabs, and pulverized ore-bearing rocks were prepared by standard techniques for ore microscopy, SEM and micro-PIXE studies. The slides were examined by petrological and ore microscopy to record relevant mineralogical and petrological characteristics, and to mark areas of interest for subsequent microanalysis. For SEM and micro-PIXE analyses, the samples were coated with a thin layer of carbon to make the surfaces electri- cally conducting. Facilities in the Material Characterization Laboratory of the Research Institute at King Fahd University of Petroleum \& Minerals were used for SEM measurements.

The scanning proton microprobe at the Energy Research Laboratory (ERL) of the Research Institute of King Fahd University of Petroleum \& Minerals was used to carry out the micro-PIXE measurements reported in this paper. The ERL microprobe facility has been described elsewhere [7] and its applications in geology [8], catalysts [10,11], metallurgy [9], and high tcmperature superconductors [12] have been reported. Typical resolution of the microbeam for 2.5 $\mathrm{MeV}$ protons is about 4 microns at a current of about $50 \mathrm{pA}$ and the maximum scanning range is about 0.5 $\mathrm{mm}$ in each of the $x$ and $y$ directions. A secondary electron detection system is available to quickly position the microbeam on any region of interest on the sample for subsequent PIXE analysis. From the scanned area of the sample, an average elemental composition spectrum as well as multiple elemental distribution maps in color can be produced simultaneously.

\section{Results and discussion}

Twenty samples containing various mineral phases including quartz, feldspar, muscovite, hornblende, pyrite, arsenopyrite, chalcopyrite, galena, and native gold were studied. Results of these analyses show distinctive elemental patterns and surface textural characteristics. Quartz diorite, the prominent goldbearing rock, under thin section optical microscopy revealed several interesting petrological and microstructural features. These features have significant bearing on the mineralization process and subsequent deposition of metals within quartz veins. For example, numerous dark bands were seen in a transparent quartz crystal. These dark bands often contain arsenopyrite, pyrite, pyrrhotite, chalcopyrite, and galena. In addition, trace amounts of gold and silver also associate with other base metals $(\mathrm{Cu}, \mathrm{Fe}$, and $\mathrm{Zn}_{\mathrm{n}}$ in these bands. From microstructural point of view, these dark bands exhibit brecciation phenomenon and indicate preexisting shear-induced fractures. These fractures ultimately became pathways for subsequent mineralizing ore fluid which 
followed these microconduits and selectively precipitated base metals and auriferous deposits. This phenomenon is evidenced in a SEM micrograph of a quartz sample in Fig. 1. The presence of preexisting fractures/lineaments within the Precambrian rocks has been documented by several workers in the past $[13,14]$ and it is believed that the large-scale mineralization process and subsequent younger sedimentary rocks were heavily influenced by these ancient lineaments.

The micro-PIXE elemental spectra (Figs. 2 and 3) show the presence of several trace elements including $\mathrm{Ti}, \mathrm{Cr}, \mathrm{Mn}, \mathrm{Cu}, \mathrm{Zn}, \mathrm{Rb}$, and possibly $\mathrm{Au}$. Detection of these trace elements in the ppm range is an advantage of the micro-PIXE technique over SEM which provides mostly the major elemental data. The absolute concentrations of the trace elements given in Table 1 are derived by normalizing their relative concentrations obtained by the PIXE measurements with the absolute concentration of a major element (Si or $\mathrm{Ca}$ ) measured by SEM. Such a normalization protocol was applied successfully by Hickmott and Baldridge [15].

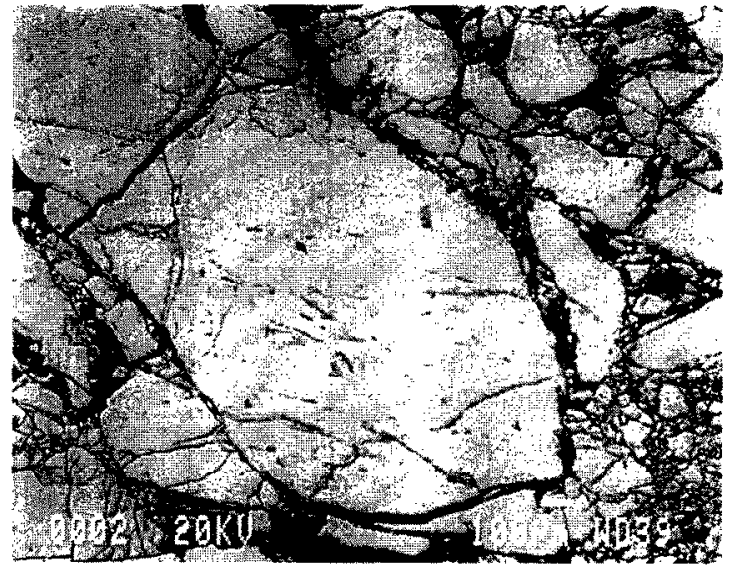

Fig. 1. SEM microphotograph showing transparent britle quartz erisscrossed by numerous metal-rich dark bands. These dark bands often contain arsenopyrite, pyrite, pyrrohtite, chalcopyrite, and galena, and are associated with traces of gold and silver.

Elemental distribution maps obtained by microPIXE are shown in Figs. 4 and 5. Distributions of K, $\mathrm{Fe}$, and $\mathrm{Ca}$ roughly anticorrelate with Si (Fig. 4). A crescentic shaped micro feature is enclosed by a

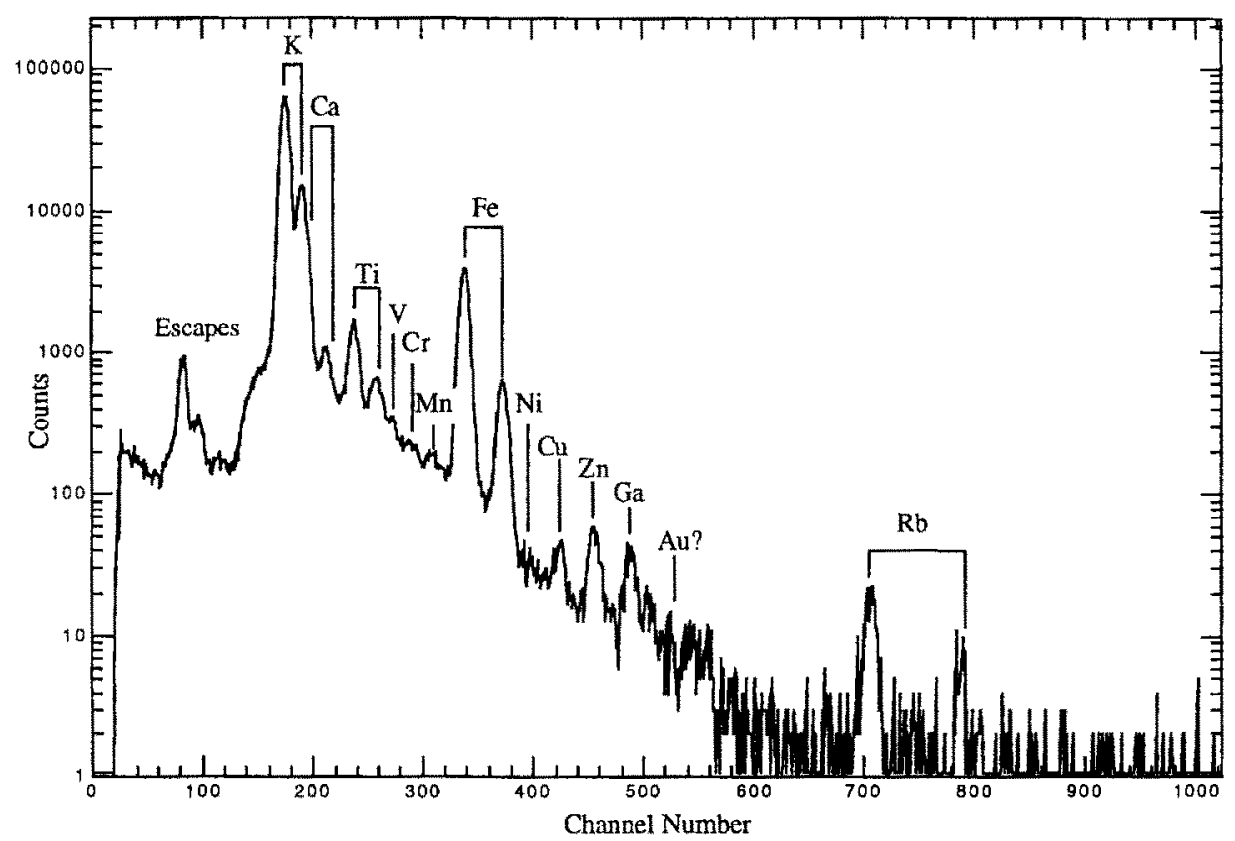

Fig. 2. Micro-PIXE elemental spectrum from a $0.5 \times 0.5 \mathrm{~mm}^{2}$ area on a dark metal-rich grain showing the presence of several trace elements. A carbon absorber was used in front of the $\mathrm{Si}(\mathrm{Li})$ detector. 


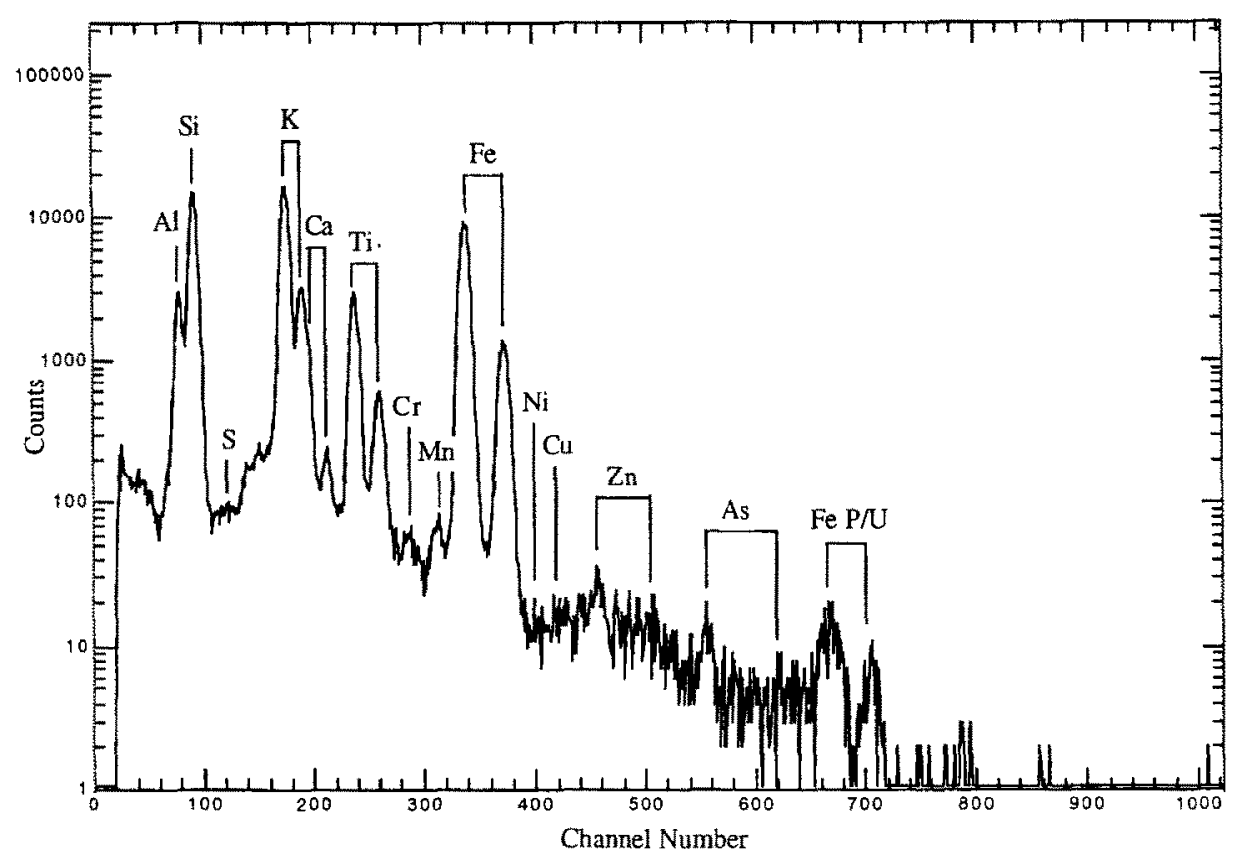

Fig. 3. Micro-PIXE elemental spectrum from a $0.5 \times 0.5 \mathrm{~mm}^{2}$ area on a transparent grain mainly composed of quartz, showing the presence of several trace elements.

quartz grain (Fig. 4) and indicates its possible entrapment within the quartz during crystallization. Presence of several micro-conduits within feldspar and

Table I

Concentrations of various major and trace elements in Proterozoic ore-bearing rocks from the An Najadi region in Saudi Arabia from micro-PIXE and SEM measurements

\begin{tabular}{ll}
\hline Element & Concentration (ppm) \\
\hline $\mathrm{Al}$ & $47185 \pm 2512$ \\
$\mathrm{Si}$ & $380000 \pm 15018$ \\
$\mathrm{~S}$ & $630 \pm 109$ \\
$\mathrm{~K}$ & $194403 \pm 9120$ \\
$\mathrm{Ca}$ & $1890 \pm 108$ \\
$\mathrm{Ti}$ & $6920 \pm 1.52$ \\
$\mathrm{~V}$ & $<\mathrm{MDL}$ of 2.8 \\
$\mathrm{Cr}$ & $60 \pm 12$ \\
$\mathrm{Mn}$ & $190 \pm 29$ \\
$\mathrm{Fe}$ & $32715 \pm 1550$ \\
$\mathrm{Ni}$ & $<\mathrm{MDL}$ of 1.5 \\
$\mathrm{Cu}$ & $195 \pm 24$ \\
$\mathrm{Zn}$ & $315 \pm 36$ \\
$\mathrm{Ga}$ & $330 \pm 34$ \\
$\mathrm{As}$ & $440 \pm 39$ \\
$\mathrm{Rb}$ & $1000 \pm 92$ \\
$\mathrm{Au}$ & $<\mathrm{MDL}$ of 2.4 \\
\hline
\end{tabular}

quartz grains were clearly revealed by the clemental distribution maps in Fig. 5. This sort of microstructural behavior of the host grains demonstrates the presence of brittle fracture prior to the oncoming ore-bearing fluid. Hence, an epithermal origin for the metal deposits is suggested.

Genesis of gold in these regions is described by previous workers by employing three contrasting geological models: (1) a composite quartz vein model with quartz veins often reaching as much as $10 \mathrm{~m}$ and carrying pyrite, arsenopyrite, base metals, and gold; (2) a granite-pegmatite model with brecciated quartz-feldspar, recrystallized quartz, pyrite, sphalerite, chalcopyrite, gold, and tungsten; and (3) a ferruginous chert model with pyrite-bearing gold [16]. It seems probable that existing model numbers 1 and 2 may provide some plausible explanation for the concentration of metals in the An Najadi regions. However, considering the thickness, brecciation, and the nature of mineralization, one can argue for an epithermal origin whercby orc-bcaring fluid followed a preexisting intricate fracture pattern and subsequently deposited metals along these microconduits. Models 1 and 2 also require mainly acidic ore-bearing 


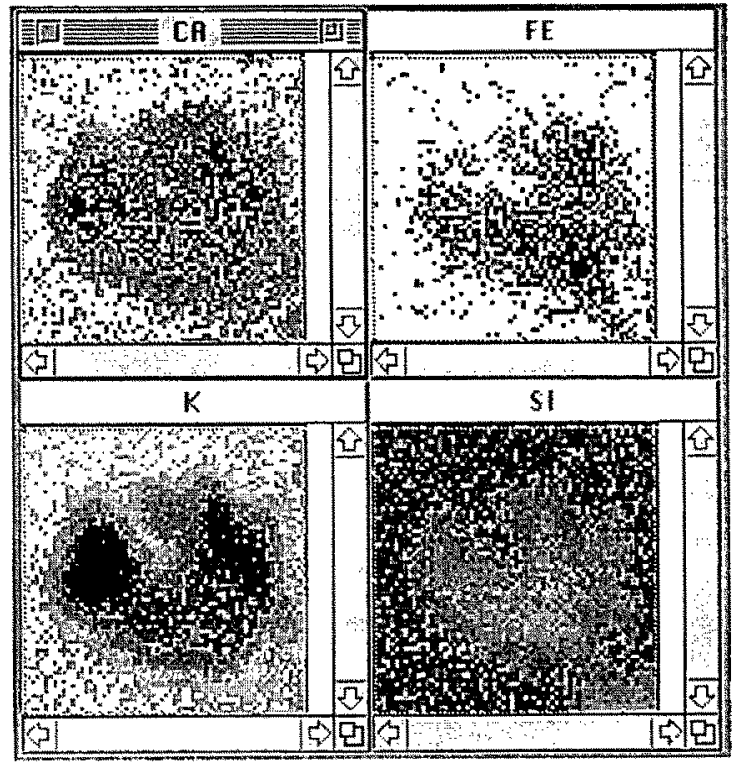

Fig. 4. Micro-PIXE elemental distribution maps from a $0.5 \times 0.5$ $\mathrm{mm}^{2}$ area on a transparent grain mainly composed of quartz. Darker shades indicate higher concentrations. The crescent-shaped distributions of $\mathrm{K}, \mathrm{Fe}$, and $\mathrm{Ca}$ inside the quartz grain indicate the entrapment of these clements during the crystallization of quartz.

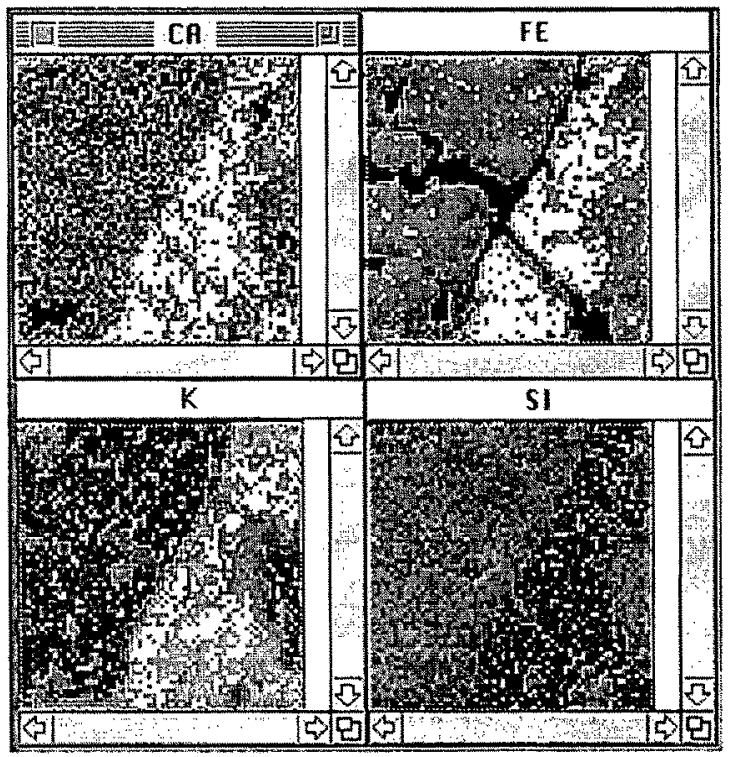

Fig. 5. Micro-PIXE elemental distribution maps from a $0.5 \times 0.5$ $\mathrm{mm}^{2}$ area around a contact zone between a feldsuar and a quartz. Darker shades indicate higher concentrations. Fe can be seen to follow several micro-conduits within the feldspar and quartz grains indicating fracture-controlled epithermal mineralization. fluid. However, the presence of substantial amounts of arsenopyrite in our samples makes it highly unlikely that the ore-bearing solution in the An Najadi was purely acidic [17]. The timing of mineralization can not be exactly determined from this study and an isotopic study may indicate this mineralization time [18]. Model number 3 invokes a volcaniclastic origin of metals including gold mineralization and does not reflect metal paragenesis in these regions. Furthermore model 3 requires an ocean floor setting where a hot mineralizing solution usually precipitates sulfide-rich minerals. The An Najadi region was thought to be part of the continental accretion phenomenon during the Proterozoic period which indicates within-plate mineralization [19-21].

\section{Conclusions}

Microanalytical techniques used in this study have been useful in understanding some of the geological and geochemical aspects related to metal genesis in the An Najadi and adjacent regions. Primary mineralization seems to be concentrated along brecciated quartz veins within quartz diorite intrusives. These brecciation phenomena predate the mineralization process. It seems probable that preexisting fractures/lineaments were reactivated prior to the mineralization process and created microconduits for orebearing solution to pass by. Precious metals including gold show a selective preference in terms of association and usually $\mathrm{As}, \mathrm{Fe}, \mathrm{Zn}$, and $\mathrm{Cu}$ seem to correlate well among each other. An epithermal, within-plate origin is suggested for the metal concentrations in this region.

\section{Acknowledgements}

The authors acknowledge the support of the Research Institute of King Fahd University of Petroleum \& Minerals for this work. Thanks are due to the personnel in the Earth Sciences Department for assistance in sample preparation and S. Madhusoodhanan Pillai, Tandetron Accelerator Operator for technical assistance. Sincere appreciations are due to the man- 
agement of the Sukhaybarat Gold Mine, especially Sameh Jalal, Kurt Christensen, Juhani Nylander, and J.S. Portacio, Jr. for their cooperation.

\section{References}

[1] G. Bogue, Report of Directorate General of Mineral Resources, Saudi Arabia (1953) p. 27.

[2] G.A. Dirom. Report of Directorate General of Mineral Resources, Saudi Arabia (1946) p. 23

[3] K.S. Kellogy, United States Geological Survey, Open File Report 04-01 (1983) p. I.

[4] A. Kinsawi, J. Saudi Arabian Archeology 7 (1983) 76.

[5] J.A. Huckerby, Institute of Mining and Metallurgy Transactions B17 (1983) 171.

[6] Report of the Deputy Ministry for Mineral Resources. Ministry of Petroleum \& Mineral Resources, Saudi Arabia (1984) p. 1 .

[7] M. Ahmed, J. Nickel, A. Hallak, R. Abdel-Aal, A. Coban, H. Al-Juwair, M. Aldaous, Nucl. Instr. and Mcth. B 82 (1993) 584.

[8] N.I. Khandaker, M. Ahmed, M.A. Garwan, Nucl. Instr, and Meth. B 109/110 (1996) 587.
[9] M. Ahmed, A. Rahman, J. Nickel, M. Garwan, Nucl. Instr. and Meth. B 103 (1995) 233.

[10] A. Rahman, M. Ahmed, M. Mohammad, Appl. Catal. 12] (1995) 203.

[11] A.N. Shuaib, J. Nickel, M. Ahmed, Nucl. Instr. and Meth. B $103(1995) 68$.

[12] M. Faiz, M. Ahmed, M. Al-Ohali, Nucl. Instr. and Meth. B 114 (1996) 138.

[13] R.S. Lewis, R.H. Al-Otaibi, H.W. Schull and M.B. Talib, in: Proc. of the Saudi Society of Earth Sciences, Riyadh, Oct. $16-18(1996)$ p. 62

[14] P.R. Johnson, in: Proc. of the Saudi Society of Earth Sciences, Riyadh. Oct. 16-18 (1994) p. 39

[15] D.D. Hicknolt, W.S. Baldridge, Economic Geology 90 (1995) 246.

[16] J.S. Stacey, C. Hedge, Geology 12 (1984) 310

[17] M.S. Sahi, in: Proc. of the Saudi Society of Earth Sciences, Riyadh, Oct. 24-26 (1996) p. 70.

[18] IS Stacey, RD Doe, RI Roberts, M.H Delevaux, IW. Gramlich, Contributions to Min. \& Pet. 74 (1980) 175.

[19] P.R. Johnson, G.J. Vranas, Precambrian Research 25 (1984) 329.

[20] E.T.C. Spooner, C.T. Barrie, Economic Geology 88 (1993) 1307.

[21] V.E. Camp, Geol. Soc. Am. Bulletin 95 (1984) 913. 